\title{
Interdisciplinaridade e temas socioambientais
}

Susana Cesco

$\triangle$ ÁREA interdisciplinar é, segundo a Capes, a área do conhecimento que mais cresce no Brasil. Talvez fruto da necessidade de estabelecer novos diálogos com a sociedade e ajudar a responder os problemas complexos e híbridos que enfrentamos. Nas palavras de Claude Raynaut, diretor de Pesquisa do Centro $\mathrm{Na}$ cional da Pesquisa Científica da França, em entrevista à Assessoria de Comunicação da Capes no ano de 2010, "várias das questões cruciais da sociedade exigem uma abordagem interdisciplinar, [... a vida não vê fronteiras disciplinares". ${ }^{1}$ Há, especialmente nas atuais questões que envolvem meio ambiente e desenvolvimento - econômico e sustentável dimensões políticas, técnicas, culturais e inter-relacionais que só serão percebidas e respondidas quando ultrapassarmos as barreiras disciplinares.

O desafio da interdisciplinaridade passa, inicialmente, pela questão institucional e estende-se até a forma e os métodos de avaliação dos trabalhos interdisciplinares. Ainda segundo Raynaut

É claro que o recorte disciplinar deu nascimento a territórios de poder, territórios de identificação, que fazem com que seja difícil ultrapassar as barreiras e promover a colaboração. Outro desafio é mais intelectual, trata-se de fazer colaborar disciplinas que não vão enxergar os mesmos níveis de realidade. Em particular, fazer colaborar disciplinas que trabalham questões concretas, práticas e materiais da realidade com outras que trabalham com dimensões não tão pal-

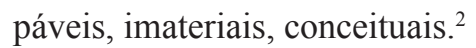

Em um tempo em que o desenvolvi- mento sustentável, a segurança alimentar e a relação do homem com o meio ambiente estão na pauta de políticos e pesquisadores e estimulam ações econômicas e políticas, novas perguntas também estão sendo formuladas. Nesse cenário surgem dois livros que comprovam a existência de propostas concretas de análise dessas novas ações e reações sociais em ralação ao meio ambiente do ponto de vista interdisciplinar.

O estado atual do debate acerca do pensamento crítico socioambiental apresenta perspectivas animadoras por meio dos livros Práticas socioambientais na pós-graduação brasileira e Rumo ao pensamento critico socioambiental, produzidos pelo Programa de Pós-Graduação em Ciência Ambiental (Procam), da Universidade de São Paulo (USP) e editados pela Annablume em 2010. O trabalho de Wagner Costa Ribeiro como organizador dessas duas coletâneas de textos sobre a questão socioambiental, vista e analisada por pesquisadores brasileiros, é uma indicação de que várias instituições de ensino superior estão formando novos profissionais e debatendo novas ideias utilizando a abordagem interdisciplinar como estratégia.

Textos de autores importantes como José Eli da Veiga e Pedro Roberto Jacobi, entre outros, ao lado de nomes novos de mestres, doutores e/ou doutorandos, indicam que a temática socioambiental não se restringe a uma ou outra área específica do conhecimento, e que, para realmente compreender o tema em sua totalidade, é importante uma análise interdisciplinar, sem conceitos preconcebidos. 
No livro Práticas socioambientais na pós-graduação brasileira, professores apresentam os programas de Pós-Graduação com temáticas socioambientais existentes em instituições de todo o Brasil como o doutorado em Ciências Ambientais da Universidade Federal de Goiás (UFG), o doutorado em Ambiente e Sociedade da Universidade de Campinas (Unicamp), o Programa de Pós-Graduação em Desenvolvimento Sustentável da Universidade de Brasília (UnB), a Pós-Graduação em Desenvolvimento e Meio Ambiente no Nordeste da Universidade Federal do Ceará (UFC), o Programa de mestrado em Meio Ambiente e Desenvolvimento da Universidade Federal do Paraná (UFPR) e o Programa de Pós-Graduação em Ciência Ambiental da Universidade Federal Fluminense (UFF). Esses programas, em sua maioria, criados nos anos 1990, já formaram muitos mestres e doutores cujos trabalhos evidenciam que a convergência de disciplinas de áreas diversas permitiu que a proposta interdisciplinar desses cursos se consolidasse.

Em Rumo ao pensamento crítico socioambiental, os resultados de experiências que foram analisadas em dissertações e teses são apresentados em forma de artigos. Escritos, em grande parte, por professores e alunos e/ou ex-alunos do Programa de Pós-Graduação em Ciência Ambiental, os artigos trazem a experiência interdisciplinar em seu conteúdo. Além disso, demonstram que há uma efetiva inserção de seus autores no mercado de trabalho e no ambiente acadêmico, muitas vezes retornando à suas áreas de origem disciplinar levando consigo essa experiência.

A natureza interdisciplinar dos Programas de Pós-Graduação apresentados e discutidos em Práticas socioambientais na pós-graduação brasileira é percebida por meio da estrutura dos textos que apresentam os Programas desde sua fundação, descrevendo motivações e anseios dos idealizadores, passando por questões de autoafirmação e de criação de um novo campo. Por fim, apresentam como resultados mestres e doutores formados e sua inserção, individualmente e como grupo, nas próprias instituições formadoras ou em outras, contribuindo para difundir e consolidar a interdisciplinaridade.

Para além da Universidade e dos Programas de Pós-Graduação, as questões socioambientais passam para o campo concreto com os textos que relatam a implantação de cursos para lideres comunitários, potenciais difusores desse saber como o "Projeto escola socioambiental de líderes comunitários" de autoria de alguns professores e pós-graduandos da Universidade Federal de Pernambuco (UFPE) e projetos socioambientais para crianças que vivem em comunidades vizinhas a áreas de proteção permanente, caso do texto "Concepções e percepção ambiental de alunos e professores de escolas do entorno de uma unidade de conservação do semiárido nordestino", elaborado por pesquisadores e professores da Universidade Federal do Rio Grande do Norte (UFRN).

Em Rumo ao pensamento crítico socioambiental, a análise de questões como programas de recursos hídricos, cooperativas de coleta seletiva, princípio da precaução, problemas ambientais gerados pela agroindústria, demonstram que novas abordagens estão enriquecendo o debate e criando uma bibliografia interdisciplinar cujo foco é a temática socioambiental. Como resultado, percebe-se que temas transversais importantes a di- 


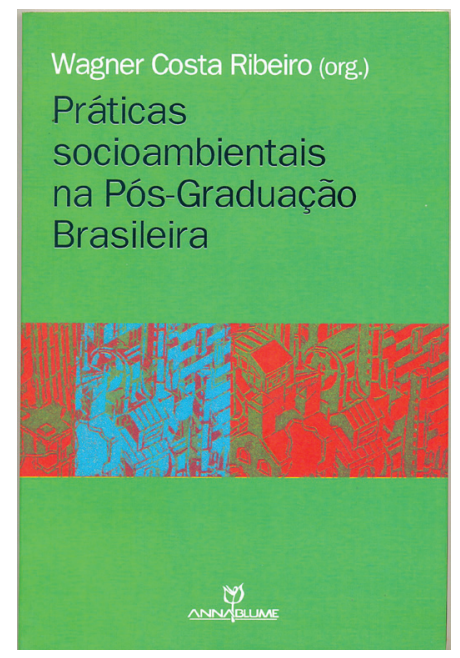

RIBEIRO, W. da C. (Org.) Práticas socioambientais na pós-graduação brasileira.

São Paulo: Annablume, 2010. 226p.

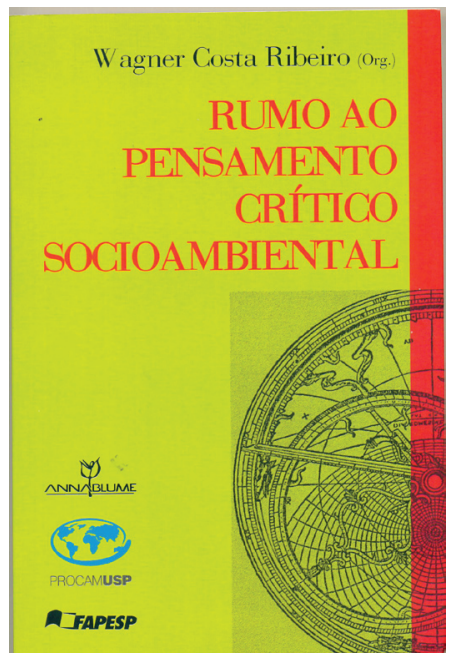

RIBEIRO, W. da C. (Org.) Rumo ao pensamento crítico socioambiental. São Paulo: Annablume, 2010. 330p. ferentes áreas do conhecimento, quando analisados do ponto de vista socioambiental, permitem que conceitos importantes sejam debatidos e novas práticas, estimuladas.

A natureza interdisciplinar desses Programas de Pós-Graduação e os trabalhos produzidos por seus professores, alunos e ex-alunos são revelados à medida que representam problemas científicos ambientais situados em interfaces do conhecimento disciplinar e que demandam abordagens metodológicas apropriadas. Não podemos nos esquecer de que a formulação de políticas públicas, no caso aquelas em que o foco esteja nas questões ambientais, pode ser objeto de análise de pesquisas científicas sobre o tema como, no contrafluxo, esses mesmos trabalhos tornarem-se referências para a formulação de políticas para o setor.

Os problemas analisados não se restringem à ordem política ou econômica, ou às áreas disciplinares da biologia ou da sociologia. No campo intelectual e acadêmico, em especial nos Programas de Pós-Graduação de natureza interdisciplinar com temáticas socioambientais, os trabalhos produzidos vão ao encontro de uma preocupação que, atualmente, perpassa todas as esferas da sociedade, que é a relação do homem com o meio ambiente. Essa questão se reflete em preocupações práticas tais como a destruição da vida, o declínio da capacidade reprodutiva da terra como uma entidade viva e a deterioração da qualidade de vida do ser humano.

É importante destacar que os trabalhos acadêmicos desenvolvidos nos programas interdisciplinares apresentados no livro Práticas socioambientais na pós-graduação brasileira e os textos resultantes de estudos específicos apresentados em Rumo ao pensamento crítico socioambiental são criteriosos em suas 
pesquisas e desenvolvimento. Além disso, como Ferreira, Ferreira e Joly ressaltam, “a formação acadêmica necessária à realidade atual deve sustentar-se plenamente em linhas de pesquisa sólidas, mas em constante abertura ao diálogo e a novos autores e idéias sem, contudo, abdicar dos critérios e exigências de cada disciplina” (p.38).

Esses cursos de Pós-Graduação interdisciplinares desfragmentam e ampliam as possibilidades de análise do mundo e da relação do homem com o meio ambiente, separada, por tanto tempo, em diferentes áreas disciplinares. As questões ambientais ultrapassam os limites da biologia, da geografia ou da sociologia, e exigem estruturas mais pluralistas e universais de abordagem. Os resultados apresentados nessas coletâneas são exemplo disso e reforçam a ideia de que temas do dia a dia como a viabilidade de cooperativas de coleta seletiva, o principio da precaução, os problemas ambientais gerados pela agroindústria e cursos para lideres comunitários, quando transformados em objeto de estudo, contribuem para aprimorar as práticas cotidianas.

Todos os textos e os Programas de Pós-Graduação organizados nessas duas coletâneas pelo professor Wagner Costa Ribeiro demonstram que os temas socioambientais estão sendo debatidos de forma qualificada por profissionais formados em instituições que estão dispostas/abertas para o debate interdisciplinar e que foram precursoras na criação de cursos com esse enfoque. Os resultados começam a aparecer e os livros aqui apresentados ampliam a visibilidade desses cursos e de seus alunos e professores, apresentando o campo e mostrando alguns "frutos" para alunos, profissionais e parceiros, atuais e/ou potenciais.

\section{Notas}

1 Claude Raynaut, entrevista à Assessoria de Comunicação da Capes em 30.11.2010. Portal Capes, disponível em: <http:// www.capes.gov.br> Acesso em: 28 fev. 2011.

2 Ibidem.
Susana Cesco é doutora em História Social IFCS/UFRJ, bolsista Prodoc/Capes no CPDA/UFRRJ.

@ - susanacesco@gmail.com /

susanacesco@yahoo.com.br 